close attentions of orthopaedic nursing staff. On one occasion she tried to reach the roof, apparently in order to throw herself off; and on another she insisted that she was now going home because she felt quite well. The disruption to the ward on a busy operating morning was considerable and it therefore seemed sensible to arrange admission to the Psychiatric Department, another building on the same site. The patient was unwilling to go and the Duty Approved Social Worker was unwilling to allow a Section 2 to be enforced, claiming that the 1983 Mental Health Act specifically excludes alcoholism as a reason for detention.

These were the circumstances under which it seemed necessary, once the acute situation had resolved itself, to gain a qualified opinion such as that provided by $\mathrm{Mr}$ G. K. Roberts of the Medical Defence Union.

Sutton Hospital

LARRY CULLIFORD

Sutton, Surrey

\section{Care of the mentally ill}

DeAR SiRS

I wonder if I can take up various points in the Bulletin of June 1986 which sensibly might be linked together in one letter.

I was very pleased to see in the Irish Division Report the recommendations on services to mentally handicapped people who have psychiatric illnesses. This was an issue which MIND debated at its Annual Conference in 1984 and we held a one day conference on the issue in the same year. Many carers and representatives of the statutory services attended in an attempt to find some coherent way of dealing with such needs. The overwhelming view was that mentally ill people who have mental illness should be treated in appropriate mental health services rather than in mental handicap services, that appropriate training should be given to staff of the psychiatric services in the specific needs of mentally handicapped people, and that we need a much greater awareness of the incidence of depressive and psychotic illnesses in mental handicapped people. I hope that the College can continue to put emphasis on this issue.

Mental health problems in mentally handicapped people often manifest in late adolescence, and young adults generally are another group badly served by our current services. There appears to be a general tide of unhappiness sweeping through young people. Whilst many have adjusted well to the lack of job prospects and large amounts of undirected leisure time, others, especially those from unstable backgrounds, are demonstrating that loss of hope can lead to pathology.

MIND has been running an exciting project funded by the Manpower Services Commission in Wolverhampton for educationally backward adolescents with severe behavioural disorders. The project has been beneficial in keeping some youngsters out of longstay hospitals and in offering a resource to hard pressed careers officers and social workers. A small research project undertaken by the West Midlands Regional Office of MIND demonstrated an increasing con- cern by local education authorities throughout the country. It would be interesting to hear from child and adolescent psychiatrists their referral rates and what services are available in their areas.

Which brings me to the HAS and their recent useful report, $A$ Bridge Over Troubled Waters. The HAS seems to be coming in for some criticism from psychiatry for its tough and voluble concern for the quality of care in institutions. Such scrutiny is, however, essential if we are to ensure the best possible human service delivery wherever it occurs, and to constantly reappraise the way we provide our care. Visits by the HAS must be seen as positive ways of offering a new perspective on an institution, rather than being seen as some negative attempt to criticise individuals. Peter Horrocks and his team are to be congratulated on involving a range of professional staff from the statutory and voluntary agencies in the adolescents' work; and it is encouraging that the HAS reports are now public, leading to greater understanding of the problems faced in hospitals and to a lack of secrecy over the difficulties they uncover.

Finally may I turn to Bob Bluglass's report, Parliamentary News. He reports on the House of Lords debate on the care of mentally ill people giving some space to Lord Mottistone's rather trenchant views of the patients' or consumer movements. It is worth stating that MIND does not support the Campaign against Psychiatric Oppression or the Network of Alternatives to Psychiatry or any other particular consumer group. It is true, and most of your readers will be aware, that MIND has always been pro-consumer and is attempting to support the development of a strong consumer voice. Clearly we believe Lord Mottistone is wrong to suggest that CAPO is evil, though he is of course entitled to his view that they may be misguided.

Lord Ennals in replying to this challenge stated that he knew nothing about 'patients' power' but said that 'most patients have no power at all and those whose only residence is a mental hospital do not even have a vote, let alone political power or any other sort of power. I believe that people who are patients must be consulted about their own future. They are people as well as patients'.

It was good that the Lords had such a lengthy debate on the care of mentally ill people and that they reflected the view of the College, of the National Schizophrenia Fellowship and a variety of other organisations. Lord Rea quoted MIND's calculation that a sum of at least $£ 500$ million needs to be transferred to local authorities for services to mentally handicapped people, and a similar sum is needed for services to people with mental illnesses. This is a message we must get over to politicians and planners-alternatives to institutions are not a cheap option; replacing an underfunded institutional service with an underfunded community service is a recipe for disaster. We must all fight together to get the cash to develop a truly comprehensive mental health service.

Christopher Heginbotham

MIND

National Director

22 Harley Street, London WI 